\title{
An exploratory study of short-term camping in Antarctica: Hormonal and mood states changes
}

\author{
Ygor Antônio Tinoco Martins ${ }^{1}$, Michele Macedo Moraes ${ }^{2,3}$, Thiago Teixeira \\ Mendes $^{4}$, Chams Bicalho Maluf ${ }^{5}$, Roberto Vagner Puglia Ladeira ${ }^{3}$, Samuel \\ Penna Wanner ${ }^{1}$, Danusa Dias Soares ${ }^{1}$, Rosa Maria Esteves Arantes ${ }^{2,3 *}$ \\ ${ }^{1}$ Exercise Physiology Laboratory, School of Physical Education, Physiotherapy and Oc- \\ cupational Therapy, Universidade Federal de Minas Gerais, Belo Horizonte, MG, Brazil \\ ${ }^{2}$ Department of Pathology, Institute of Biological Sciences, Universidade Federal de \\ Minas Gerais, Belo Horizonte, MG, Brazil \\ ${ }^{3}$ Center for Newborn Screening and Genetics Diagnosis, Faculty of Medicine, Universi- \\ dade Federal de Minas Gerais (Núcleo de Ações e Pesquisa em Apoio Diagnóstico da \\ Faculdade de Medicina da UFMG -FM/UFMG), Belo Horizonte, MG, Brazil \\ ${ }^{4}$ Center for Natural and Human Sciences, Health and Technology, Universidade Federal \\ do Maranhão, Pinheiro, MA, Brazil \\ ${ }^{5}$ Department of Clinical Pathology, Faculty of Medicine, Universidade Federal de \\ Minas Gerais, Belo Horizonte, MG, Brazil
}

\begin{abstract}
Long-term Antarctic expedition's studies indicated harmful or positive behavioral and psychophysiological adaptive changes that arise from adversities in isolated, confined, and extreme environments. Whereas most of the published studies focused on overwintering situations, most Brazilian Antarctic Program summer expeditions consist of short-term stays. We evaluated the influence of a permanence in Antarctic short-term (13-day) summer camp on the hormonal responses and mood states in eight volunteers. Data collection was carried out at the beginning (initial measure, days 3 to 5) and the end (final measurement, days 10 to 12) of the camping. Morning and evening samples of saliva were obtained to measure the testosterone and cortisol concentrations. Morning blood drops were used to determine thyroid-stimulating hormone (TSH) and thyroxine (T4) concentration. The volunteers also answered a mood states questionnaire. During the short-term camp, T4 $\left(3.92 \pm 0.75 v s 2.21 \pm 0.71 \mu \mathrm{g} . \mathrm{dL}^{-1}\right)$ and T4/TSH $(3.16 \pm 0.97 v s$ $1.79 \pm 0.74 \mathrm{AU})$ reduced, without concomitant changes in TSH $(1.28 \pm 0.17$ vs $1.30 \pm$ $\left.0.09 \mu \mathrm{U} \cdot \mathrm{mL}^{-1}\right)$, and salivary cortisol increased $\left(2,392 \pm 1,153\right.$ vs 4,440 $\left.\pm 1,941 \mathrm{pg} \cdot \mathrm{mL}^{-1}\right)$ resulting in greater cortisol amplitude (calculated from the difference between morning and evening measurement, $1,400 \pm 1,442$ vs 3,230 $\pm 2,046)$. In men, testosterone increased as well $(26.2 \pm 12.5$ vs $67.8 \pm 45.8$, all differences with $\mathrm{P}<0.05)$. There was a moderate effect in mood states evidenced by increased anger and fatigue, and reduced vigor. At the end of the camp, the change in cortisol correlated with anger, and the final cortisol values with anger and tension. We concluded that staying in a short-term summer camp in Antarctica induced endocrine and mood state changes, indicators of stress reaction.
\end{abstract}

Received September 7, 2021, accepted December 16, 2021.

*Corresponding author: R.M.E. Arantes <rosa@icb.ufmg.br; rosa.esteves.arantes@gmail.com> Acknowledgements: The authors thank the military personnel involved in the Brazilian OPERANTAR for logistical support and the volunteers who participated in this study. We thank the Center for Newborn Screening and Genetics Diagnosis (NUPAD), especially the technical contribution of Alex da Costa Guedes. We also thank Professor Andres Zarankin for his collaboration with the present study. 
Y.A.T. MARTINS et al.

Key words: confinement, isolation, expedition, neuroendocrine, polar, stress

DOI: $10.5817 / \mathrm{CPR} 2021-2-24$

\section{Introduction}

Every year, several researchers travel to the Antarctic field to carry out data collection that may last for days, weeks, or even months. ICE elements - i.e., isolation, confinement and extreme situations - are environment-dependent (Moraes et al. 2020, Bartone et al. 2018, Sandal et al. 2006), and are potentially experienced in Antarctic summer camps because of the almost $24 \mathrm{~h}$ of luminosity, significant cold, and adverse conditions (storms, white-out situations, and displacements in rouge terrains), associated with communication restrictions (Moraes et al. 2018, Pattyn et al. 2017, Palinkas and Suedfeld 2008).

Prolonged exposure to luminosity influences circadian concentrations of hormones associated with the dark-light cycle; for example, stimulating cortisol (Kanikowska et al. 2019, Scheer and Buijs 1999) and inhibiting thyroid-stimulating hormone (TSH) (Hassi et al. 2001, Palinkas et al. 2001). Cortisol is a catabolic (Brillon et al. 1995, Simmons et al. 1984) and stress-related hormone (Russell and Lightman 2019) that inhibits testosterone secretion (Cumming et al. 1983); thus, changes in cortisol concentration alter the body anabolic-catabolic balance. Also, cortisol presents an inhibitory effect on TSH secretion (Van der Spoel et al. 2021, Re et al. 1976). The stress of moderate and intense physical exertion is an additional stimulus for cortisol secretion (Hill et al. 2008). Noteworthy to mention that our previous work showed that the physiological strain associated with labor in Antarctica consisted of low-to-moderateintensity efforts, with moments of highintensity physical effort during displacements (reaching 80-90\% of maximum heart rate) (Moraes et al. 2018). Besides, cold exposure is a physical-psychological stressor stimuli (Schwabe et al. 2008, Dickerson and Kemeny 2004) that increases cortisol concentration (Vitale et al. 2018, Izawa et al. 2009, Pääkkönen and Leppäluoto 2002, Chrousos and Gold 1992). Thyroid hormones regulate metabolism (Mullur et al. 2014, Silva 1995), increasing metabolic heat production (Silva 2001, Reed et al. 2001, Do et al. 1996), which, in turn, helps to defend the body temperature. Cold can induce T4 (thyroxine) conversion to triiodothyronine (T3), reducing T4 concentration (Mullur et al. 2014). Divergent responses to the cold environment exposure were reported (Pääkkönen and Leppäluoto 2002); while severe cold exposure in water relates to increased TSH (Kovaničová et al. 2020), mild cold conditions can decrease or even not affect TSH concentration (Kovaničová et al. 2020, Iwen et al. 2017, Leppäluoto et al. 1988).

Antarctic ICE conditions influence endocrine responses, which can affect mood states (Pattyn et al. 2017, Palinkas and Suedfeld 2008, Palinkas et al. 2007, Harinath et al. 2005, Xu et al. 2003, Palinkas et al. 2001). Chronic cortisol elevation can generate maladaptive responses such as depressed or elevated mood (i.e., depression or mania), irritability, lability, and anxiety (Brown 2009), as glucocorticoids alter the brain's neural circuitry by modulating neurotransmitters and neurotrophic factors (Belanoff et al. 2001). Elevated TSH accompanied by reduced T3 and T4 is associated with winter syndrome mood fluctuations, characterized by depressive symptoms (e.g., high levels of anger and irritability described as "polar syndrome") 
(Palinkas et al. 2001, 1996). As glucocorticoids and TSH affect emotional states (Wirth et al. 2011, Kritz-Silverstein et al. 2009, Xu et al. 2003), these hormones can be a physiological link between staying in ICE environments and changes in states of humor.

Studies about long-term expeditions have reported the harmful behavioral and psychophysiological alterations resulting from prolonged wintering exposure to isolation, confinement, and extreme environments (Zimmer et al. 2013). However, salutogenic effects may also arise from successful adaption to environmental adversities due to an increased sense of selfsufficiency and personal growth (Zimmer et al. 2013, Palinkas and Suedfeld 2008). In this sense, a previous study showed that for a three-week summer camping expedition to Antarctica, the vigor scores were constantly higher than the negative categories (Moraes et al. 2020). This may be associated with the season of the year, the duration, and conditions of stay in Antarctica. Considering that several countries carry out summer camps in Antarctica, it is relevant to know the possible hormonal and mood changes in these camps, with different durations (from days to months).

Previous studies have reported hormonal and mood state changes during prolonged summer camps in Antarctica, i.e., three or more weeks (Moraes et al. 2020, Pattyn et al. 2017, Harinath et al. 2005, Farrace et al. 1999), and after returning from a long expedition (Woods et al. 2015,

\section{Material and Methods}

\section{Ethics}

This study followed the regulations established by the Brazilian National Health Council (resolution 466/2012) and was approved by the research ethics committee of the Universidade Federal de Minas Gerais (protocol number 56360516.5.0000.5149).
Harinath et al. 2005). Although these earlier studies have focused on the effects of medium- to long-term camps, it is also possible to expect hormonal changes in short-term stays, given the different stimuli provided by the Antarctic environmental conditions. Relevantly, while in a longterm camp, individuals spend more days exposed to polar environmental conditions, in a short-term camp, fewer days to carry out the work, and less time between assembly and disassembly of the camp structure, can add up as a stress factor. Therefore, the physiological and mood responses may differ with the length of stay in the camp. Notably, short-term camping may also provide relevant information about early human adaptations to adverse conditions.

The present study aims to evaluate the influence of a permanence during 10to 12-day Antarctic camping compared to initial days in camping on hormonal responses (i.e., TSH, T4, cortisol, and testosterone) and mood states. We hypothesized that intense and prolonged exposure to day light and low ambient temperatures would reduce TSH and T4 concentrations during a short-term camp. Altogether with other potential stressors (e.g., displacements in rough terrains), the ICE conditions would increase the cortisol concentration, favoring a catabolic state (i.e., a reduced testosterone/cortisol ratio) a TSH inhibition and negative mood states (i.e., anger, tension, fatigue, depression, and confusion).
The volunteers were informed about the research objectives and all the experimental procedures before giving their written informed consent for participation in this study. 
Y.A.T. MARTINS et al.

\section{Subjects and experimental approach to the problem}

Eight nonmilitary individuals (five men and three women) that took part in a journey to Antarctica to conduct fieldwork (i.e., prospection) were recruited to participate in this study (Table 1). Seven volunteers were researchers, and the other one was a mountaineer. The expedition took place in January of 2017, during the Antarctic summer season, and lasted 19 days: 6 days onboard the Brazilian navy polar ship "Almirante Maximiano" (number of tack $\mathrm{H}-41$ ), and 13 days (12 nights) in a camp settled on the Byers Peninsula (Livingstone Island), located on the South Shetland Islands $\left(62^{\circ} 39.851^{\prime} \mathrm{S}, 61^{\circ} 05.998^{\prime}\right.$ W). During the field expedition, the volunteers spent their first two days assembling the camping site structures. The first data collection (initial measure) was performed from the $3^{\text {rd }}$ to the $5^{\text {th }}$ day and the last (final measurement) from the $10^{\text {th }}$ to $12^{\text {th }}$ day after the camp initiation. After that, the participants returned to the ship.

The field period was characterized by prolonged daylight, varying from $18 \mathrm{~h}$ 51 min. (sunrise: 3:44 a.m. / sunset: 10:35 p.m.) in the first day to $17 \mathrm{~h} 31 \mathrm{~min}$. (sunrise: 4:28 a.m. / sunset: 9:59 p.m.) in the last day of camp. Temperature and relative humidity $(\mathrm{RH})$ ranged from $-1{ }^{\circ} \mathrm{C}$ to $+6^{\circ} \mathrm{C}$ and from $42 \%$ to $95 \% \mathrm{RH}$, respectively, and gales with wind reached values up to $67 \mathrm{~km} / \mathrm{h}$ ([1] Zone-related website Time and Date, $2017 ; 13^{\text {th }}$ to $27^{\text {th }}$ January daily data from the launch of the camp until its removal can be accessed at https://www.timeanddate.com/sun/@6620 723?month=1\&year=2017[1]). During camp, individuals kept a regular diurnal schedule. Volunteers usually woke up between 06:30 a.m. and 7:30 a.m. and left their tents to arrive at the social tent for breakfast (days without data collection), walked to the work area around 9:00 a.m., returned to the camp around 5:00 p.m., and slept from a time between 9:00 p.m. and 11:00 p.m. until the next morning. During the workday, the individuals performed excavation and tasks involving the handling of artifacts. Fieldwork and camping routines were the same for all individuals. On the days of data collection, the volunteers were woken up at 06:30 a.m. and at 7:00 a.m. they moved to the laboratory tent for data collection.

\begin{tabular}{ccccc}
\hline & Age (years) & Height (cm) & Body mass (kg) & Body fat (\%) \\
\hline Mean \pm SD & $40.1 \pm 13.8$ & $168.5 \pm 9.3$ & $77.1 \pm 22.2$ & $24.2 \pm 4.9$ \\
Range & $25-65$ & $155.0-183.0$ & $54.2-120.0$ & $16.2-30.7$ \\
\hline
\end{tabular}

Table 1. Anthropometric characteristics of the volunteers $(n=8)$. Footnote: The data are expressed as means \pm SD and as the range of variation (from minimum to maximum).

\section{Measurement of anthropometric characteristics}

Body mass was measured with men wearing shorts and women wearing shorts and a top. Skinfold thickness was meas- ured in triplicates by the same investigator at seven sites - triceps, subscapular, pectoral, mid-axilla, abdominal, supra iliac, 
and mid-thigh -using a skinfold caliper (Lange, MI, USA). The body fat percentage was calculated, according to Jackson

\section{Data collection}

On data collection days, the participants were individually evaluated at the tent set up as a laboratory. The experimental procedures (i.e., saliva and blood sample collection and application of the selfreported questionnaire for mood states assessment) were carried out between 7:00

\section{Mood states questionnaire}

Mood states were assessed using the 24-item Brunel mood scale(BRUMS) (Terry et al. 2003, 1999). The questionnaire was applied on paper, and the volunteers responded using a pen. The BRUMS has six dimensions, with each dimension being composed of four items, as follows: anger (annoyed, bitter, angry, and badtempered), confusion (confused, muddled, mixed-up, and uncertain), depression (de-

\section{Salivary hormonal analyses}

The saliva samples were temporarily stored inside a styrofoam box buried in ice (about $-2.0^{\circ} \mathrm{C}$ ) in the Antarctic field and, after 13 days, transferred to a $-80^{\circ} \mathrm{C}$ freezer inside the ship. The samples were kept frozen until processing and analysis. It is worth highlighting the long-term stability of salivary cortisol and testosterone samples, which remain viable and stable for analyzes after one to three months, even at temperatures higher $\left(+4^{\circ} \mathrm{C}\right.$ or above $)$ that those maintained in the present study (Durdiaková et al. 2013, Garde and Hansen 2005).

A $400-\mu \mathrm{L}$ saliva sample was used to measure free-testosterone concentration by and Pollock's equations (Jackson and Pollock 1978).

and 7:30 a.m. Data collection was performed with volunteers in a fasted state, after waking up, and before carrying out the displacement and fieldwork activities. Saliva samples were also collected at 7:00 p.m.

pressed, downhearted, unhappy, and miserable), fatigue (worn out, exhausted, sleepy and tired), tension (panicky, anxious, worried, and nervous), vigor (lively, energetic, active, and alert). Each item is preceded by the question "How do you feel right now?" and should be answered on a 5-point scale (from 0 to 4). Therefore, the total score for each dimension ranges from 0 to 16 .

enzyme immunoassay (Triturus ELISA Instrument, Grifols, Spain) (Blanco et al. 2003), and a 300- $\mu \mathrm{L}$ saliva sample was used to measure cortisol concentration by electrochemiluminescence (Modular ERoche, Switzerland) (Carrozza et al. 2010). As cortisol concentration is higher during the morning than at night (Wright et al. 2015), the cortisol amplitude was calculated as the difference between the 7:00 a.m. and 7:00 p.m. concentrations. All analyzes were performed in the same analytical run, minimizing the inter-assay coefficient of variation (CV): free-testosterone $=12.0 \%$ and cortisol $=3.6 \%$. 


\section{Blood hormonal analyses}

For measuring thyroid hormone concentrations, drops of blood were collected on a filter paper (Whatman S\&S 903 Screening Cards, Life Sciences, GE Healthcare, US), dried horizontally, stored in plastic bags with silica, and kept away from exposure to light and hot temperatures. Dried blood spot disks (each $3.2 \mathrm{~mm}$ in diameter) were plated, diluted in europium buffer solution, and analyzed by time-resolved two-site fluoroimmunoassay with direct double-sandwich technique (AutoDELFIA Neonatal hTSH and Auto DELFIA Neonatal T4; WallacOy, Fin-

\section{Statistical analyses}

Initially, to assess the distribution of data, the Shapiro-Wilk test was used. The parameters evaluated did not show a significant departure from a normal distribution. The equal variance was tested and confirmed using the Levene Median test. Throughout the text, in the tables and in Fig. 1, data are shown as mean $\pm S D$ of the group values.

Paired Student's t-tests were used to compare mood states, salivary hormonal responses (i.e., cortisol, cortisol amplitude, testosterone, testosterone/cortisol ratio), and blood hormonal responses (i.e., $\mathrm{TSH}, \mathrm{T} 4$, and T4/TSH ratio) between the beginning and end of the camp. Thus, the mean and SD of the difference (end minus beginning; MD and SDD), degrees of freedom (DF), and t-value for all data were also presented. The t-value and DF are presented as $\mathrm{t}(\mathrm{DF})$. The $\alpha$ level was set at 0.05 . All the analyses described previously were performed using the SigmaPlot 11.0 software (Systat Software Inc.). Pearson's correlation was used to evaluate the land), as previously reported in a similar study (Manousou et al. 2020, Moraes et al. 2020, Magalhães et al. 2018). TSH sensitivity is typically better than $2 \mu \mathrm{U} / \mathrm{mL}$, and $\mathrm{T} 4$ sensitivity is typically better than $1.5 \mu \mathrm{g} / \mathrm{dL}$. There is no relevant cross-reactivity to report (only T4 has cross-reactivity with D-Thyroxine (30\%), an isomer of thyroxine) ([2] B032-312 AutoDELFIA Neonatal hTSH, 2016; [3] B065-112 Auto DELFIA Neonatal Thyroxine (T4), 2016). All analyzes were performed in the same analytical run, minimizing the inter-assay $\mathrm{CV}: \mathrm{TSH}=12.8 \%$ and $\mathrm{T} 4=12.2 \%$.

strength of a linear association between two variables by determining the $r$ coefficient. The $r$ coefficient effect size $(E S)$ values were classified as small (ES $0.2-$ 0.5 or $-0.2--0.5$ ), medium (ES $0.5-0.8$ or $-0.5--0.8)$, and large $(>0.8$ or $<-0.8)$ (Sullivan and Feinn 2012).

Considering the reduced number of subjects joining the expedition $(\mathrm{n}=8)$, we presented the statistical significance by $P$-value and the substantive significance by calculating Cohen's $d E S$ as a supplementary analysis (Sullivan and Feinn 2012). Cohen's $d E S$ allowed the assessment of the magnitude of differences between data and was calculated by subtracting the mean value of one time point from the mean value of the time point to which it was being compared.

The Cohen's $d E S$ values were classified as small (ES $0.2-0.5$ ), medium (ES $0.5-0.8)$, large (ES $0.8-1.3)$, and very large $(E S>1.3)$ (Sullivan and Feinn 2012). 


\section{Results}

During the short-term camp, there was no statistically significant difference in TSH concentration between the first and the last measurement (Initial: $1.28 \pm 0.17 \mu \mathrm{U} . \mathrm{mL}^{-1}$, Final: $1.30 \pm 0.09 \mu \mathrm{U} \cdot \mathrm{mL}^{-1} ; \mathrm{MD}=-0.026$; $\mathrm{SDD}=0.11 ; P=0.53 ; \mathrm{t}(7)=-0.656 ; E S=$ $0.19)$ (Fig. 1A), whereas there was a significant very large decrease in $\mathrm{T} 4$ concentration (Initial: $3.92 \pm 0.75 \mu \mathrm{g} . \mathrm{dL}^{-1}$, Final: $2.21 \pm 0.71 \mu \mathrm{g} . \mathrm{dL}^{-1} ; \mathrm{MD}=1.71, \mathrm{SDD}=$ $0.75 ; P<0.001 ; \mathrm{t}(7)=6.491, E S=2.35)$ (Fig. 1B). These hormonal responses led to a reduction in the T4/TSH ratio (Table 2).

Cortisol concentration at 7:00 a.m. was largely increased during the camp (Initial: $2,392 \pm 1,153$ pg.mL ${ }^{-1}$, Final: 4,440 \pm 1,941 pg. $\mathrm{mL}^{-1} ; \mathrm{MD}=-2,048 ; \mathrm{SDD}=2,016$; $P=0.02 ; \mathrm{t}(7)=-2.873 ; E S=1.29$ )(Fig. 1C); whereas there were no statistically significant changes in cortisol at 7:00 p.m. (Initial: $992.3 \pm 500.4$ pg. $\mathrm{mL}^{-1}$, Final: $1,209.8$ \pm 887.5 pg. $\mathrm{mL}^{-1} ; \mathrm{MD}=-217.5 ; \mathrm{SDD}=$ $1,108 ; P=0.59 ; \mathrm{t}(7)=-0.555 ; E S=0.30)$ (Fig. 1D). The specific increase in morning cortisol resulted in greater cortisol amplitude at the end compared to the begin- ning of the Antarctic camp (Table 2).

For free-testosterone concentration measured at 7:00 a.m. the result of the comparison between means did not reach statistical significance; however, there was a moderate effect size for the comparison (Initial: $20.2 \pm 12.7$ pg.mL ${ }^{-1}$, Final: $45.7 \pm$ 46.1 pg. $\mathrm{mL}^{-1} ; \mathrm{MD}=-25.47$; $\mathrm{SDD}=35.4$; $P=0.08 ; \mathrm{t}(7)=-2.033 ; E S=0.75)$ (Fig. $1 \mathrm{E})$. When considering only men, it was observed a large effect size in the morning free-testosterone (Initial: $26.2 \pm 12.5, \mathrm{Fi}$ nal: $67.8 \pm 45.8 ; \mathrm{MD}=-41.5 ; \mathrm{SDD}=36.5$; $P=0.06 ; \mathrm{t}(4)=-2.542 ; E S=1.24, \mathrm{n}=5)$. The individual variation values, calculated as 'Individual variation $=[$ (Final value - Initial value) *100]/Initial value module' can be accessed in the supplementary material (Supplemental material, Table S1). During this short-term camp, there were no changes in testosterone measured at 7:00 p.m. $(\mathrm{MD}=0.96 ; \mathrm{SDD}=9.62$; $P=0.78, \mathrm{t}(7)=0.284 ; E S=0.06)($ Fig. $1 \mathrm{~F})$ and in the testosterone/cortisol ratio at 7:00 a.m. or at 7:00 p.m. (Table 2).

\begin{tabular}{|c|c|c|c|c|c|c|c|}
\hline & $\begin{array}{c}\text { Initial } \\
\text { measure }\end{array}$ & $\begin{array}{c}\text { Final } \\
\text { measure }\end{array}$ & MD & SDD & t-value & $P$-value & $E S$ \\
\hline $\begin{array}{l}\text { T4/TSH at 7:00 a.m. } \\
\text { (AU) }\end{array}$ & $\begin{array}{c}3.16 \\
\pm 0.97\end{array}$ & $\begin{array}{l}1.79 * \mathrm{VL} \\
\pm 0.74\end{array}$ & 1.37 & 0.66 & 5.87 & $<0.001$ & 1.59 \\
\hline $\begin{array}{l}\text { Cortisol amplitude } \\
\left(\text { pg.mL } \mathrm{mL}^{-1}\right)\end{array}$ & $\begin{array}{r}1400 \\
\pm 1442\end{array}$ & $\begin{array}{l}3230 * \mathrm{~L} \\
\pm 2046\end{array}$ & -1830 & 2221 & -2.33 & 0.05 & 1.03 \\
\hline $\begin{array}{l}\text { Testosterone/Cortisol } \\
\text { at 7:00 a.m. }\left(\times 10^{-2}\right)\end{array}$ & $\begin{array}{c}1.44 \\
\pm 1.80\end{array}$ & $\begin{array}{c}1.03 \\
\pm 0.92\end{array}$ & 0.40 & 1.66 & 0.69 & 0.51 & 0.28 \\
\hline $\begin{array}{l}\text { Testosterone/Cortisol } \\
\text { at 7:00 p.m. }\left(\times 10^{-2}\right)\end{array}$ & $\begin{array}{c}2.28 \\
\pm 1.85\end{array}$ & $\begin{array}{c}2.48 \\
\pm 3.33\end{array}$ & -0.21 & 1.68 & -0.35 & 0.74 & 0.08 \\
\hline
\end{tabular}

Table 2. The T4/TSH ratio, cortisol amplitude, and testosterone/cortisol ratio at 7:00 a.m. and 7:00 p.m. in the beginning (initial measure) and at the end (final measure) of the short-term Antarctic expedition. Footnote: Cohen's d effect sizes $(E S)$ were calculated to assess the magnitude of the difference between experimental time points. $\mathrm{n}=8$. ${ }^{*}$ Significantly different $(P<0.05)$ from the initial measure. ${ }^{\mathrm{L}}$ Large effect size; ${ }^{\mathrm{VL}}$ Very large effect size. The data are expressed as means \pm standard SD. MD: mean of the difference. SDD: standard deviation of the difference. $P$-value: probability. t-value: ratio of the difference between the mean of the two sample sets and the variation that exists within the sample sets. Degrees of freedom $(D F)=7$, for all variables. 
A

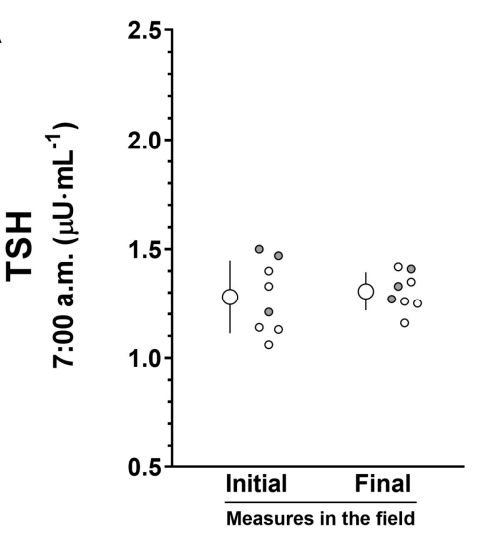

C

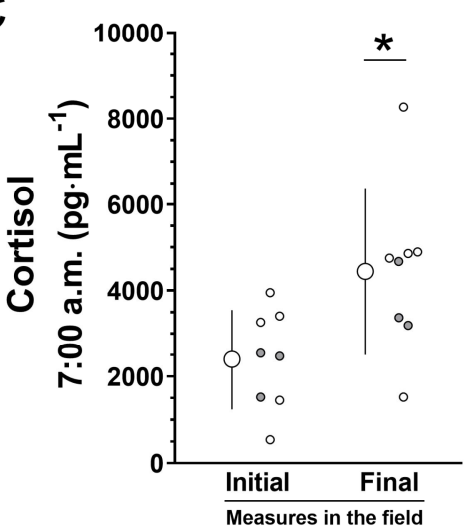

$E$

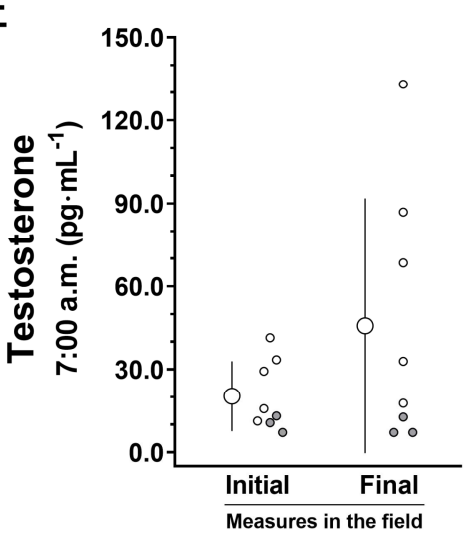

B

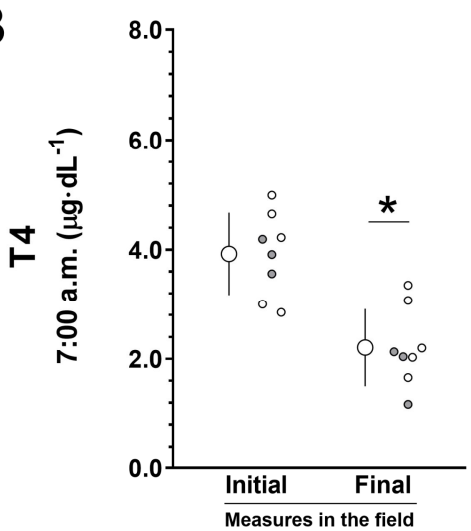

D

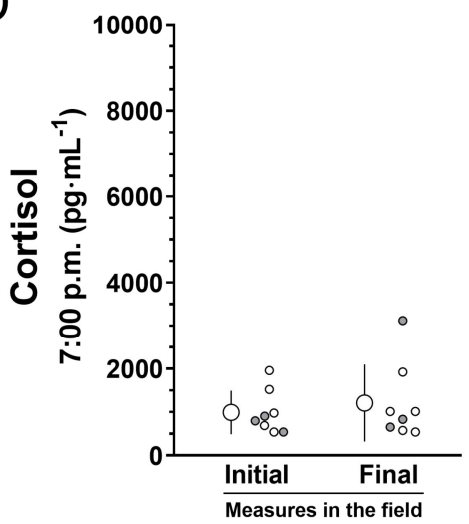

$\mathrm{F}$

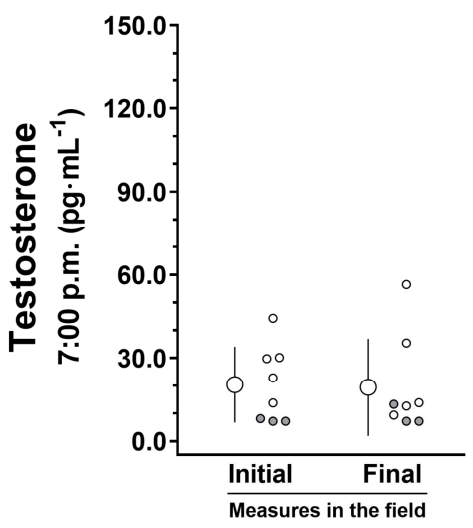

Fig. 1. Hormonal concentrations measured in the beginning (initial measure) and at the end (final measure) of the short-term Antarctic expedition. A) thyroid-stimulating hormone (TSH), B) thyroxine (T4), C) cortisol at 7:00 a.m., F) cortisol at 7:00 p.m., G) free-testosterone at 7:00 a.m., and $\mathrm{H}$ ) free-testosterone at 7:00 p.m. The data are expressed as means \pm SD. The dots represent the individual datum of men $(\circ)$ and women $(\bullet)$. *Significantly different $(P<0.05)$ from the initial measure. $\mathrm{n}=8$. 
Regarding the mood states, there were no statistically significant changes $(\mathrm{P}>0.05)$; however, Cohens' effect size showed a moderate effect to increase in anger and fatigue alongside a moderate reduction in vigor between the initial and the final measurement, with no relevant effect on the other mood states (Table 3).

\begin{tabular}{cccccccc}
\hline & $\begin{array}{c}\text { Initial } \\
\text { measure }\end{array}$ & $\begin{array}{c}\text { Final } \\
\text { measure }\end{array}$ & MD & SDD & t-value & P-value & ES \\
\hline Anger & $1.8 \pm 1.7$ & $3.1 \pm 2.5$ & -1.3 & 3.3 & -1.01 & 0.35 & $0.60^{\mathrm{M}}$ \\
Confusion & $1.8 \pm 2.3$ & $1.3 \pm 2.0$ & 0.6 & 2.7 & 0.56 & 0.60 & 0.26 \\
Depression & $1.4 \pm 2.1$ & $0.7 \pm 0.8$ & 0.7 & 2.6 & 0.74 & 0.49 & 0.44 \\
Fatigue & $3.1 \pm 3.2$ & $5.3 \pm 2.3$ & -2.1 & 4.6 & -1.23 & 0.26 & $0.76^{\mathrm{M}}$ \\
Tension & $2.4 \pm 2.8$ & $3.4 \pm 2.5$ & -1.0 & 4.2 & -0.63 & 0.55 & 0.38 \\
Vigor & $5.1 \pm 1.9$ & $3.8 \pm 2.5$ & 1.3 & 1.8 & 1.89 & 0.11 & $0.60^{\mathrm{M}}$ \\
\hline
\end{tabular}

Table 3. Mood states measured in the beginning (initial measure) and at the end (final measure) of the short-term Antarctic expedition. Footnote: Cohen's d effect sizes $(E S)$ were calculated to assess the magnitude of the difference between experimental time points. $n=7$, because the mood states data were not accessed in one volunteer. ${ }^{\mathrm{M}}$ Moderate effect size. The data are expressed as means \pm SD. MD: mean of the difference. SDD: standard deviation of the difference. $P$-value: probability. t-value: ratio of the difference between the mean of the two sample sets and the variation that exists within the sample sets. Degrees of freedom $(D F)=6$, for all variables.

Correlation analysis was used to investigate the association between short-term camping-induced changes in hormonal responses and mood states. There were moderate to large inverse correlations between the decrement in T4/TSH (final measure initial measure, values in modulus) and tension (Fig. 2A). There was a one nonsignificant (but with a tendency towards significance) correlation between the decrement in T4/TSH and anger (Fig. 2B) at the end of the field, with no significant correlations with the other mood states (Fig. 2C-F). Also, a statistically significant direct large correlation between the increment in cortisol (final measure - initial measure) and anger at the end of the field was observed (Fig. 2H), but no significant correlations with the other mood states (Fig. 2G and Fig. 2I-L). The increase in cortisol showed an inverse large correlation with the change in T4/TSH (Fig. 3). Cortisol absolute value at the end of the field camp also showed a significant moderate correlation with anger (Fig. $2 \mathrm{~N}$ ) and a significant large correlation with tension (Fig. 2M), though no other significant correlations were observed (Fig. 2O-R). There were no significant correlations between the change in testosterone or absolute testosterone concentration and mood states. 

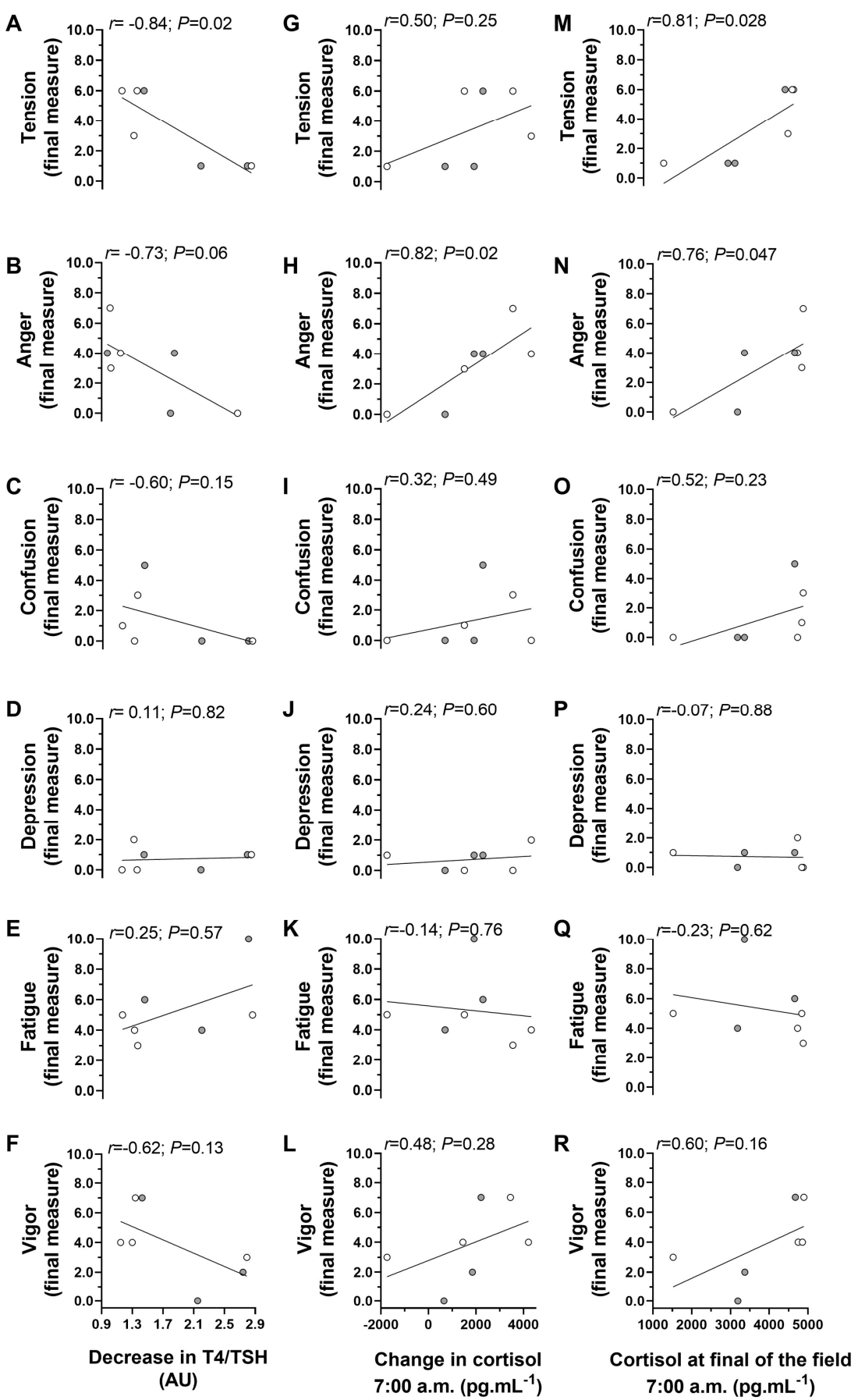

Fig. 2. Correlations between mood states and change in the T4 / TSH ratio (final measure - initial measure) (A-F), the change in cortisol (final measure - initial measure) (G-L) and the absolute value of cortisol at the final of the field camp (M-R). $n=7$. The dots represent the individual measurements of men $(\circ)$ and women $(\bullet)$. 


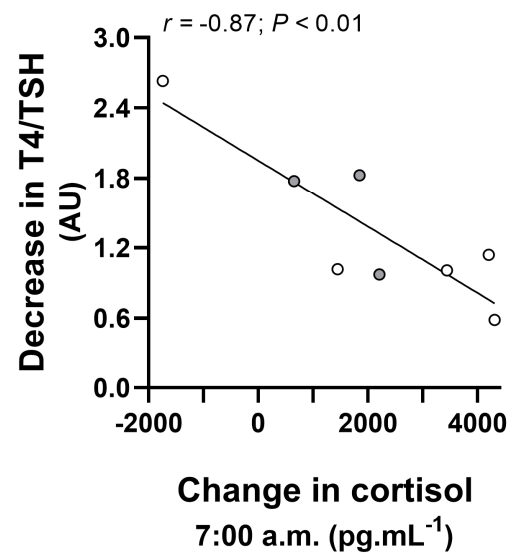

Fig. 3. Correlation between the increase in cortisol during the short-term camp (final measure initial measure) and the change in the T4 / TSH ratio (final measure - initial measure, values in modulus), $\mathrm{n}=8$. The dots represent the individual measurements of men $(\circ)$ and women $(\bullet)$.

\section{Discussion}

The permanence in a short-term camp during the Antarctic summer induced neuroendocrine and mood state changes, as evidenced by reduced $\mathrm{T} 4$ concentration, $\mathrm{T} 4 / \mathrm{TSH}$ ratio, and vigor, as well as morning increased testosterone in men and increased cortisol concentrations, anger, and fatigue at final moment compared to initial days of camping. Importantly, some of these hormonal and mood state modifications were associated. Thus, the present study showed that hormonal changes are not restricted to long-term Antarctic camps but also occur during short-term camps.

Regarding thyroid hormones, there was no change in TSH during permanence in the field, which is in line with previous observations made by Moraes et al. (2020) after 11 days of camping compared to the $4^{\text {th }}$ day in camp. The short-term camp also reduced $\mathrm{T} 4$ concentration, which reflects two main possibilities. First, this result may evidence a changed functioning of the thyroid axis, with less T4 release to the same TSH concentration (as shown by the T4/TSH ratio). Alternatively, as cold exposure diverts T3 to the skeletal muscle, T4 reduction may also reflect an acclimation- mediated increase in tissue T4 to T3 conversion by deiodinase enzymes (Mullur et al. 2014, Silva 2001, Do et al. 1996). The impact of cold on our volunteers' physiology was evidenced by reduced face temperature (O'Brien et al. 2011, Gavhed et al. 2000, LeBlanc et al. 1976) just after 20 minutes of exposure to the Antarctic environment (Supplemental material, table S2). Of note, Reed et al. (1990) reported simultaneous increases in TSH and resting metabolic rate over a year in an Antarctic station alongside a decline in T4. In the present study, we observed a decline in T4 but no changes in TSH. The conflicting result of TSH could be explained by the effect of luminosity in Antarctic summer camp inhibiting TSH release (Moraes et al. 2020, Hassi et al. 2001). Also, Woods et al. (2015) reported that a 42-day expedition increased T3 concentration, reinforcing the increased conversion of $\mathrm{T} 4$ to $\mathrm{T} 3$ hypothesis. In addition, T4 reduction may reflect an increase in its accumulation in tissues (Tsibulnikov et al. 2020).

Another possible explanation for the reduced T4 concentration would be an activation of the hypothalamus-pituitary- 
adrenal axis. Stressors act in the central nervous system (CNS) and can cause a decrease in thyrotropin-releasing hormone (TRH) mRNA and plasma TSH levels (Martí et al. 1996, Kakucska et al. 1995), leading to T3 and T4 decreases (Helmreich et al. 2005, Bianco et al. 1987). However, considering that TSH did not decrease between the two camp measures, the T4 reduction is not a result of an inhibitory effect on TSH release due to increased CNS cortisol. Interestingly, this reduction in T4 was not observed in the previous study that compared the measurements obtained on $4^{\text {th }}$ day to those obtained on the $11^{\text {th }}$ day in camp (Moraes et al. 2020), suggesting that specific camping conditions may influence the T4 response. It is worth mentioning that the present study was conducted in January, when Antarctica's extreme brightness is even more prolonged, with three additional hours of daylight than in February, the month when the previous study (Moraes et al. 2020) was carried out. As thyroid hormones present a circadian rhythm and respond to light stimuli, the maximum summer brightness experienced by volunteers in the present study may have favored the T4 reduction (Palinkas et al. 2001, Hassi et al. 2001).

Palinkas et al. (2001) proposed that cold-induced skeletal muscle T3 uptake and the subsequent T4 to T3 conversion reduce the availability of both thyroid hormones to CNS and precipitate mood states disturbances. It is worth noting, that T4 and $\mathrm{T} 3$ receptors are distributed in the brain and prevalent in limbic system structures implicated in mood (Bauer et al. 2008, Köhrle 2000). Experimental evidence (mainly from animal studies) supports the hypothesis that thyroid status influences the serotoninergic system in the adult brain (Bauer et al. 2008, 2002, 2001). In this sense, increasing thyroid hormone levels elevated serotonin (5-HT) neurotransmission in the cortex or whole brain (increasing concentration of 5-HT, its precursors, and metabolites) (Kulikov et al.
1999, Bauer et al. 2008, 2002). Bauer et al. (2008) summarized this interaction proposing that thyroid hormones may influence the serotonergic system by reducing the sensitivity of $5-\mathrm{HT} 1_{\mathrm{A}}$ autoreceptors in the raphe nuclei and increasing $5-\mathrm{HT}_{2}$ receptor sensitivity. It is also suggested that thyroid hormones interact with other neurotransmitter systems involved in mood regulation, including the dopaminergic system (Bauer et al. 2008, Atterwill 1981). According to Palinkas et al. (2001), these mood state disturbances may lead to a further decline in T3 and T4 levels, which in turn increase TSH through stimulation of the hypothalamus-thyroid axis via negative feedback loops, and consequently induce the increased availability of T3 and $\mathrm{T} 4$, attenuating negative mood states.

In our study, we observed a reduction in T4 and consequently decreased the T4/ $\mathrm{TSH}$ ratio. Unexpectedly, the T4/TSH ratio reduction was associated with less anger and tension at the end of the field camp. One possibility is that the observed association may reflect the occurrence of negative feedback loops, as proposed by Palinkas et al. (2001), with a lower T4/TSH ratio reflecting increased $\mathrm{TSH}$ secretion induced by reduced availability of T3 and T4. Since the reduced TSH is associated with the severity of mood symptoms (Larsen et al. 2004), the relative increase in TSH, as observed, could improve mood states. However, it is possible to consider that the present association may not represent the cause-and-effect relationship. Alternatively, it is worth noting that cortisol values at the end of the camp were positively associated with anger and tension, agreeing with previous studies showing a correlation between increased cortisol levels and stress perception (Hargreaves 1990). Also, the increase in cortisol is inversely correlated with the T4/TSH reduction. As cortisol inhibits the deionization of T4 (Toyoda et al. 2009, Helmreich et al. 2005, Hidal and Kaplan 1988), this correlation may reflect the interaction 
of the two hormones. Thus, the inverse relationship between $\mathrm{T} 4 / \mathrm{TSH}$ ratio reduction with anger and tension may reflect (i) the interaction of cortisol with $\mathrm{T} 4$ and (ii) the effect of cortisol on mood states. In this sense, an inverse relationship between the reduction of T4/TSH and cortisol variation should be further investigated as a mechanist interaction.

The increase in cortisol may reflect a possible significant physical demand (Moraes et al. 2018) and environmental stress of an Antarctic camp. In this sense, the volunteers reported increased fatigue (worn out, exhausted, sleepy and tired) and reduced vigor (lively, energetic, active, and alert), indicating worsening in subjective indexes of physiological strain at the end of the camp. It is also possible that the increase in cortisol reflects environmental stress, including an augmented exposure to light (Kanikowska et al. 2019, Leproult et al. 2001, Scheer and Buijs 1999), given the days with almost $24 \mathrm{~h}$ of light during summer camps in Antarctica. The higher morning cortisol concentration led to an increased cortisol amplitude in the second week of camping. This result agrees with the upward trend observed by Moraes et al. (2020) but contradicts Pattyn et al. (2017), as the latter study did not report changes in cortisol circadian amplitude after three weeks of camping. Notably, Pattyn et al. (2017) compared the cortisol secretion curve during $24 \mathrm{~h}$ (from samples collected every $2 \mathrm{~h}$ ) to curves previously reported for healthy subjects in normal circumstances; thus, there was no comparison between the beginning and end of a specific field situation. The data in the present study and those in Moraes et al. (2020) and Pattyn et al. (2017) studies still differ from the results of Farrace et al. (1999). These authors reported a reduction in cortisol after more prolonged camping in Antarctica, lasting two months. Therefore, a short- or medium-duration camp may not be sufficiently long to shift hormones acrophase towards the later hours of the morn- ing; as suggested by Farrace et al. (1999). This shift occurs due to the lack of dark/ light cycles. Similar to Farrace et al. (1999), Gagnon et al. (2011) showed a reduction in cortisol after returning a long-term expedition (56 days), with $850 \mathrm{~km}$ crossing at the North Pole. The authors argue that post-expedition reduction in cortisol may relate to whole-body anabolism following catabolism during crossing due to energetic deficiency, with a $10 \mathrm{~kg}$ reduction in body mass. In the present study, the short stay in the field did not seem enough for this possible inhibition of cortisol, notwithstanding the free-testosterone increase in the men. In summary, we suggest that physiological strain, augmented exposure to light, and the stressful demands of a short-term camp (such as the start of disassembly after a few days of setting up a camp) were predominant over the cortisol response.

Despite the elevation in cortisol concentration, for men at morning free-testosterone also increased at the end of the fieldwork. This is an unexpected result because cortisol inhibits testosterone secretion (Cumming et al. 1983). The unchanged testosterone/cortisol ratio contradicts earlier studies showing a shift towards a catabolic hormonal profile in the Antarctic field (Moraes et al. 2020, Anton-Solanas et al. 2016). However, our results reinforce previous findings of Woods et al. (2015) that testosterone reduction is not the only possible response in the field. Woods et al. (2015) reported an increase in total testosterone, free testosterone, and sex hormonebinding globulin after a scientific expedition lasting 42 days, a response that the author, who controlled the diet of the volunteers, attributed to maintenance of a good nutritional status and body mass.

During the fieldwork, our volunteers performed tasks that require physical effort (Moraes et al. 2018), as carrying out displacements in rugged and snow-covered terrain using heavy clothing and fieldwork of excavating, which may have stimulated 
the increase in testosterone concentration (Crewther et al. 2014, Kraemer 1988). Therefore, physical efforts have possibly resulted in an anabolic stimulus within a short-term field period, as observed by a lack of difference in the testosterone/cortisol ratio. In this sense, further studies should be conducted to investigate the caloric and macronutrient intake during different camp periods (from weeks to months) and in diverse groups. It is worth noting that increased testosterone in men only indicates a sex-specific response, possibly due to the absence of Leydig cells in women, since Leydig cells are likely to be involved in the exercise-induced increase in testosterone in men (Vingren et al. 2010).

The medical and psychological assistance aimed to prepare individuals for coping with ICE environments is usually carried out based on expectations for longterm, over-wintering subjects. However, our data highlights that distress related to social and environmental characteristics of short-term camping, during summer expeditions, should not be disregarded, as the existence of stressful stimuli could reduce individual and team performance in this extreme situation and lead to increased risk for the participants of expeditions. Hereafter, it is necessary to assess the mechanistic interactions between physiological changes and mood states on shortterm Antarctica expeditions by understanding the hypothalamic-pituitary-thyroid and hypothalamic-pituitary-adrenal axes crossregulation. Therefore, standard approaches to investigate diverse gender/sex (Strewe et al. 2019, Steinach et al. 2016, Palinkas et al. 2011) and cross-cultural/multinational (Palinkas et al. 2011, 2004; Musson et al. 2002) factors affecting the adaptation to isolated and confined environments should be extended to short-term stays in camps.

Notwithstanding the current findings clarify early adaptations to changes in environmental conditions, it must be considered that this study - a non-experimental descriptive collective case study of two- point repeated measures approach - has inherent limitations: the low number of participants and the sample's heterogeneity because of expeditions logistics. Regarding data analysis, it is necessary to consider that, for small data sets, normality tests may lack the power to detect the deviation of a given variable from normality (i.e., to reject the null hypothesis) (Ghasemi and Zahediasl 2012). Furthermore, in a group consisting of few participants, individual variability and measurement errors (systematic or not) are possible sources of bias that may affect data interpretation. Thus, the current data must be taken with caution, and the conduction of future data collection characterized by a conceptual replication of the present study is encouraged.

Other limitations of this study are the absence of pre-camp baseline measurements, assessments of physical effort in the field, and comparisons to objectively evaluate whether physical demand in the field is higher than in quotidian life.

Despite these limitations, the sample variability did not prevent the detection of statistical significance in some variables, and it was possible to observe hormonal and mood changes between the beginning and the end of the camp. Considering the possibility of differences in adaptive responses according to sex and age in ICE environments (Strewe et al. 2019, Palinkas et al. 2011), future studies should assess physiological and mood responses in more homogeneous groups concerning participants' sex and age. Also, we suggest to subsequent studies: (i) expand the assessment of stress-linked markers associated with metabolic and mood responses (e.g., catecholamines), aiming for a better understanding of the psychophysiological interactions in ICE, (ii) measure metabolic demand during rest and exertion by indirect calorimetry in different camps, to assess whether there is an adaptive response of increased metabolism at rest, as well as to compare the intensity of effort and meta- 
bolic demands during tasks and shifts, (iii) carry out baseline measurements just before the field period, (iv) include a nutritional register, considering that the absence of an energy deficit, the good nutritional status and the maintenance of body mass may be associated with an increase in the concentration of testosterone in the field (Woods et al. 2015), and (v) adopt laboratory-based experimental approaches to understanding the isolated effects of each element of ICE conditions over the psychophysiological responses observed. In addition, future studies may add monitoring the menstrual cycle in women, considering that cortisol tends to be higher in the follicular phase (Hamidovic et al. 2020).

An important issue is that exploratory research seldom allows the observation of

\section{Conclusion}

Staying in a short-term summer camp in Antarctica increased morning cortisol for both men and women and morning testosterone in men. Also, stay in the camp reduced T4 without changing TSH concentration at the final of camp compared to initial days. In conjunction with these endocrine responses, augmented perception of anger was particularly associated with increased cortisol. These endocrine and mood state changes possibly resulted from environmental stressors, such as extended day length during the Antarctic independent factors determining phenomena in a cause-and-effect relationship since, as pointed by Tipton (2012), groups in field expeditions do not encounter environmental stressors in isolation. In this sense, the mood states and hormonal changes observed in the present study reflect an integration resulting from different ICE elements or associations between them. Nonetheless, in-loco observations characterized by combined physiological stressors offer insights to identify responses (e.g., psychophysiological changes) that must be investigated under controlled conditions. Thus, in addition to the findings with high ecological validity for individuals traveling to extreme environments, the present results may contribute to design future studies in more details and a higher interpretability of physiological data. summer, augmented physical demand, and exposure to cold.

Despite exciting, these results should be taken with caution due to the small sample size and the possible impact of data variability on the statistical analyses. In this sense, future data collection with a conceptual replication of the current study is encouraged because it will contribute to understanding the psychophysiological responses during a short-term summer camp in Antarctica.

Disclosure statement - Declarations of interest: none.

\section{Authors' contributions statement}

Each author contributed individually and significantly to the development of this study and approved the final version submitted for publication. YATM, MMM, TTM, CBM, and RMEA: designed research; YATM: performed data collection in camp; YATM and MMM: performed data collection onboard the ship; RVPL, SPW, DDS, and RMEA: provided laboratory support; YATM, MMM, RVPL, SPW, DDS, and RMEA: analyzed data; MMM, YATM, and RMEA: wrote the paper; YATM, MMM, TTM, CBM, RVPL, SPW, DDS, and RMEA: edited the paper and approved the submitted version. 
Y.A.T. MARTINS et al.

\section{Financial support}

This study was supported by CNPq/MCTIC/CAPES/FNDCT/PROANTAR [grant 442645/ 2018-0]; Fundação de Amparo à Pesquisa do Estado de Minas Gerais (FAPEMIG) [grants AEC00017-18; CDS- PPM 000304/16; CBB- APQ-01419-14] and Pró-Reitoria de Pesquisa da Universidade Federal de Minas Gerais (PRPq UFMG). RMEA received research fellowship from Conselho Nacional de Desenvolvimento Científico e Tecnológico (CNPq) [grant 311976/2021-2]. This study was financed in part by the Coordenação de Aperfeiçoamento de Pessoal de Nível Superior - Brasil (CAPES) - Finance Code 001; MMM was the recipient of a post-doctoral fellowship CAPES/BRASIL [88887.321687/2019-00]. YATM was the recipient of a FAPEMIG master's fellowship.

Some of the data described in the manuscript were partially presented at the scientific meeting 'Simposio APECS-Brasil Online', 04 February 2021, Online (Web).

\section{References}

Anton-Solanas, A., O'Neill, B. V., Morris, T. E. and Dunbar, J. (2016): Physiological and cognitive responses to an Antarctic expedition: A case report. International Journal of Sports Physiology and Performance, 11(8): 1053-1059.

ATtERwiLl, C. K. (1981): Effect of acute and chronic tri-iodothyronine (T3) administration to rats on central 5-HT and dopamine-mediated behavioural responses and related brain biochemistry. Neuropharmacology, 20(2): 131-144.

Bartone, P. T., Krueger, G. P. and Bartone, J. V. (2018): Individual differences in adaptability to isolated, confined, and extreme environments. Aerospace Medicine and Human Performance, 89(6): 536-546.

BAuer, M., Whybrow, P. C. (2001): Thyroid hormone, neural tissue and mood modulation. The world journal of biological psychiatry. The official journal of the World Federation of Societies of Biological Psychiatry, 2(2): 59-69.

Bauer, M., Goetz, T., Glenn, T. and Whybrow, P. C. (2008): The thyroid-brain interaction in thyroid disorders and mood disorders. Journal of Neuroendocrinology, 20(10): 1101-1114.

BAuer, M., Heinz, A. and WhyBrow, P. C. (2002): Thyroid hormones, serotonin and mood: Of synergy and significance in the adult brain. Molecular Psychiatry, 7(2): 140-156.

Belanoff, J. K., Gross, K., Yager, A. and Schatzberg, A. F. (2001): Corticosteroids and cognition. Journal of Psychiatric Research, 35(3): 127-145.

Bianco, A. C., Nunes, M. T., Hell, N. S. and Maciel, R. M. (1987): The role of glucocorticoids in the stress-induced reduction of extrathyroidal 3,5,3'-triiodothyronine generation in rats. Endocrinology, 120(3): 1033-1038.

Blanco, S., Domínguez, J., Jiménez, O., Sánchez, D., Galí, N., Matas, L., Ausina, V. and GALIMANY, R. (2003): Evaluation of the automatic ELISA Triturus analyser. Journal of Automated Methods \& Management in Chemistry, 25(2): 31-34.

Brillon, D. J., Zheng, B., CAmpbell, R. G. and Matthews, D. E. (1995): Effect of cortisol on energy expenditure and amino acid metabolism in humans. The American Journal of Physiology, 268(3 Pt 1): E501-E513.

BROwN, E. S. (2009): Effects of glucocorticoids on mood, memory, and the hippocampus. Annals of the New York Academy of Sciences, 1179(1): 41-55.

Carrozza, C., Corsello, S. M., Paragliola, R. M., Ingraudo, F., Palumbo, S., Locantore, P., Sferrazza, A., Pontecorvi, A. and ZupPI, C. (2010): Clinical accuracy of midnight salivary cortisol measured by automated electrochemiluminescence immunoassay method in Cushing's syndrome. Annals of Clinical Biochemistry, 47(Pt 3): 228-232.

Chrousos, G. P., Gold, P. W. (1992): The concepts of stress and stress system disorders. Overview of physical and behavioral homeostasis. JAMA, 267(9): 1244-1252.

Crewther, B. T., Kilduff, L. P. and CoOK, C. J. (2014): Trained and untrained males show reliable salivary testosterone responses to a physical stimulus, but not a psychological stimulus. Journal of Endocrinological Investigation, 37(11): 1065-1072. 
Cumming, D. C., Quigley, M. E. and Yen, S. S. (1983): Acute suppression of circulating testosterone levels by cortisol in men. The Journal of Clinical Endocrinology and Metabolism, 57(3): 671-673.

DiCKERSON, S. S., KemenY, M. E. (2004): Acute stressors and cortisol responses: A theoretical integration and synthesis of laboratory research. Psychological Bulletin, 130(3): 355-391.

Do, N. V., LeMAR, H. and ReED, H. L. (1996): Thyroid hormone responses to environmental cold exposure and seasonal change: A proposed model. Endocrinology and Metabolism, 3: 7-16.

Durdiaková, J., FÁbryová, H., Koborová, I., Ostatníková, D. and Celec, P. (2013): The effects of saliva collection, handling and storage on salivary testosterone measurement. Steroids, 78(14): 1325-1331.

Farrace, S., Cenni, P., Tuozzi, G., Casagrande, M., Barbarito, B. and Peri, A. (1999): Endocrine and psychophysiological aspects of human adaptation to the extreme. Physiology \& Behavior, 66(4): 613-620.

GARde, A. H., HANSEN, A. M. (2005): Long-term stability of salivary cortisol. Scandinavian Journal of Clinical and Laboratory Investigation, 65(5): 433-436.

Gagnon, D. D., Pullinen, T., Karinen, H., RintamäKI, H. and Kyröläinen, H. (2011): Recovery of hormonal, blood lipid, and hematological profiles from a North Pole expedition. Aviation, Space, and Environmental Medicine, 82(12): 1110-1117.

Gavhed, D., Mäkinen, T., Holmér, I. and RintamäKi, H. (2000): Face temperature and cardiorespiratory responses to wind in thermoneutral and cool subjects exposed to -10 degrees C. European Journal of Applied Physiology, 83(4-5): 449-456.

Ghasemi, A., ZahediasL, S. (2021): Normality tests for statistical analysis: A guide for nonstatisticians. International Journal of Endocrinology \& Metabolism, 10(2): 486-489.

Hargreaves K. M. (1990): Neuroendocrine markers of stress. Anesthesia Progress, 37(2-3): 99-105.

Harinath, K., Malhotra, A. S., Pal, K., Prasad, R., Kumar, R. and Sawhney, R. C. (2005): Autonomic nervous system and adrenal response to cold in man at Antarctica. Wilderness \& Environmental Medicine, 16(2): 81-91.

Hassi, J., SikkilÄ, K., Ruokonen, A. and Leppäluoto, J. (2001): The pituitary-thyroid axis in healthy men living under subarctic climatological conditions. The Journal of Endocrinology, 169(1): 195-203.

Helmreich, D. L., Parfitt, D. B., Lu, X. Y., Akil, H. and Watson, S. J. (2005): Relation between the hypothalamic-pituitary-thyroid (HPT) axis and the hypothalamic-pituitary-adrenal (HPA) axis during repeated stress. Neuroendocrinology, 81(3): 183-192.

HIDAL, J. T., KAPLAN, M. M. (1988): Inhibition of thyroxine 5'-deiodination type II in cultured human placental cells by cortisol, insulin, 3', 5'-cyclic adenosine monophosphate, and butyrate. Metabolism: Clinical and Experimental, 37(7): 664-668.

Hill, E. E., Zack, E., Battaglini, C., Viru, M., Viru, A. and Hackney, A. C. (2008): Exercise and circulating cortisol levels: the intensity threshold effect. Journal of Endocrinological Investigation, 31(7): 587-591.

Iwen, K. A., Backhaus, J., Cassens, M., Waltl, M., Hedesan, O. C., Merkel, M., Heeren, J., Sina, C., Rademacher, L., Windjäger, A., Haug, A. R., Kiefer, F. W., Lehnert, H. and SCHMID, S. M. (2017): Cold-induced brown adipose tissue activity alters plasma fatty acids and improves glucose metabolism in men. The Journal of Clinical Endocrinology and Metabolism, 102(11): 4226-4234.

Izawa, S., Kim, K., Акimoto, T., Ahn, N., Lee, H. and Suzuki, K. (2009): Effects of cold environment exposure and cold acclimatization on exercise-induced salivary cortisol response. Wilderness \& Environmental Medicine, 20(3): 239-243.

JACKSON, A. S., POLLOCK, M. L. (1978): Generalized equations for predicting body density of men. The British Journal of Nutrition, 40(3): 497-504.

KAKUCSKA, I., QI, Y. and Lechan, R. M. (1995): Changes in adrenal status affect hypothalamic thyrotropin-releasing hormone gene expression in parallel with corticotropin-releasing hormone. Endocrinology, 136(7): 2795-2802. 
Kanikowska, D., Roszak, M., Rutkowski, R., Sato, M., Sikorska, D., Orzechowska, Z., BRĘBOROWICZ, A. and WitowsKi, J. (2019): Seasonal differences in rhythmicity of salivary cortisol in healthy adults. Journal of Applied Physiology, 126(3): 764-770.

KÖHRLE J. (2000): Thyroid hormone metabolism and action in the brain and pituitary. Acta Medica Austriaca, 27(1): 1-7.

Kovaničová, Z., Kurdiová, T., Baláž, M., ŠtefaničKa, P., Varga, L., Kulterer, O. C., Betz, M. J., Haug, A. R., Burger, I. A., Kiefer, F. W., Wolfrum, C., UkropcovÁ, B. and Ukropec, J. (2020): Cold exposure distinctively modulates parathyroid and thyroid hormones in coldacclimatized and non-acclimatized humans. Endocrinology, 161(7): bqaa051.

Kraemer, W. J. (1988): Endocrine responses to resistance exercise. Medicine and Science in Sports and Exercise, 20(5 Suppl): S152-S157.

Kritz-Silverstein, D., Schultz, S. T., Palinska, L. A., Wingard, D. L. and Barrett-Connor, E. (2009): The association of thyroid stimulating hormone levels with cognitive function and depressed mood: The Rancho Bernardo study. The Journal of Nutrition, Health \& Aging, 13(4): 317-321.

Kulikov, A., Moreau, X. and Jeanningros, R. (1999): Effects of experimental hypothyroidism on 5-HT1A, 5-HT2A receptors, 5-HT uptake sites and tryptophan hydroxylase activity in mature rat brain1. Neuroendocrinology, 69(6): 453-459.

Larsen, J. K., Faber, J., Christensen, E. M., Bendsen, B. B., Solstad, K., GJerris, A. and Siersbaek-Nielsen, K. (2004): Relationship between mood and TSH response to TRH stimulation in bipolar affective disorder. Psychoneuroendocrinology, 29(7): 917-924.

LeBlanc, J., Blais, B., BARABÉ, B. and CôtÉ, J. (1976): Effects of temperature and wind on facial temperature, heart rate, and sensation. Journal of Applied Physiology, 40(2): 127-131.

Leppäluoto, J., Korhonen, I., Huttunen, P. and Hassi, J. (1988): Serum levels of thyroid and adrenal hormones, testosterone, TSH, LH, GH and prolactin in men after a 2-h stay in a cold room. Acta Physiologica Scandinavica, 132(4): 543-548.

Leproult, R., Colecchia, E. F., L'Hermite-Balériaux, M. and Van Cauter, E. (2001): Transition from dim to bright light in the morning induces an immediate elevation of cortisol levels. The Journal of Clinical Endocrinology and Metabolism, 86(1): 151-157.

Magalhães, P., Miranda, C. H., Vilar, F. C., Schmidt, A., Bittar, R. R., Paixão, G., MARTineZ, E. Z. and MACiel, L. (2018): Effects of drying and storage conditions on the stability of TSH in blood spots. Archives of Endocrinology and Metabolism, 62(2): 201-204.

Manousou, S., Andersson, M., Eggertsen, R., Hunziker, S., Hulthén, L. and Nyström, H. F. (2020): Iodine deficiency in pregnant women in Sweden: A national cross-sectional study. European Journal of Nutrition, 59(6): 2535-2545.

Martí, O., GAVAldÀ, A., Jolín, T. and ARMARIO, A. (1996): Acute stress attenuates but does not abolish circadian rhythmicity of serum thyrotrophin and growth hormone in the rat. European Journal of Endocrinology, 135(6): 703-708.

Moraes, M. M., Bruzzi, R. S., Martins, Y., Mendes, T. T., Maluf, C. B., Ladeira, R., NúÑEzEspinosa, C., Soares, D. D., Wanner, S. P. and Arantes, R. (2020): Hormonal, autonomic cardiac and mood states changes during an Antarctic expedition: From ship travel to camping in Snow Island. Physiology \& Behavior, 224: 113069.

Moraes, M. M., Mendes, T. T., Martins, Y., Espinosa, C. N., Maluf, C. B., Soares, D. D., WANNER, S. P. and ARANTES, R. (2018): The changes in maximal oxygen uptake $\left(\mathrm{VO}_{2 \mathrm{MAX}}\right)$ induced by physical exertion during an Antarctic expedition depend on the initial $\mathrm{VO}_{2 \mathrm{MAX}}$ of the individuals: a case study of the Brazilian expedition. International Journal of Circumpolar Health, 77(1): 1521244.

Mullur, R., LiU, Y. Y. and Brent, G. A. (2014): Thyroid hormone regulation of metabolism. Physiological Reviews, 94(2): 355-382.

Musson, D. M., SAndal, G. M., Harper, M. L. and Helmreich, R. L. (2002): Personality testing in Antarctic expeditioners: Cross cultural comparisons and evidence for generalizability. IAF abstracts, $34^{\text {th }}$ COSPAR Scientific Assembly. 
O'Brien, C., Castellani, J. W. and Sawka, M. N. (2011): Thermal face protection delays finger cooling and improves thermal comfort during cold air exposure. European Journal of Applied Physiology, 111(12): 3097-3105.

PÄÄKKÖNEN, T., LePPÄLuoto, J. (2002): Cold exposure and hormonal secretion: A review. International Journal of Circumpolar Health, 61(3): 265-276.

Palinkas, L. A., Johnson, J. C., Boster, J. S., Rakusa-Suszczewski, S., Klopov, V. P., Fu, X. Q. and SACHDEVA, U. (2004): Cross-cultural differences in psychosocial adaptation to isolated and confined environments. Aviation, Space, and Environmental Medicine, 75(11): 973-980.

Palinkas, L. A., Keeton, K. E., Shea, C. and Leveton, L. B. (2011): Psychosocial characteristics of optimum performance in isolated and confined environments. NASA Report TM-2011216149. Hanover, MD: NASA.

PalinKas, L. A., SuEDFELD, P. (2008): Psychological effects of polar expeditions. Lancet (London, England), 371(9607): 153-163.

Palinkas, L. A., Reed, H. L., Reedy, K. R., Do, N. V., Case, H. S. and Finney, N. S. (2001): Circannual pattern of hypothalamic-pituitary-thyroid (HPT) function and mood during extended Antarctic residence. Psychoneuroendocrinology, 26(4): 421-431.

Palinkas, L. A., Reedy, K. R., Shepanek, M., Smith, M., Anghel, M., Steel, G. D., Reeves, D., CASE, H. S., Do, N. V. and ReEd, H. L. (2007): Environmental influences on hypothalamicpituitary-thyroid function and behavior in Antarctica. Physiology \& Behavior, 92(5): 790-799.

Pattyn, N., Mairesse, O., Cortoos, A., Marcoen, N., Neyt, X. and Meeusen, R. (2017): Sleep during an Antarctic summer expedition: New light on "polar insomnia". Journal of Applied Physiology (Bethesda, Md.: 1985): 122(4): 788-794.

Re, R. N., Kourides, I. A., Ridgway, E. C., Weintraub, B. D. and Maloof, F. (1976): The effect of glucocorticoid administration on human pituitary secretion of thyrotropin and prolactin. The Journal of Clinical Endocrinology and Metabolism, 43(2): 338-346.

Reed, H. L., Reedy, K. R., Palinkas, L. A., Van Do, N., Finney, N. S., Case, H. S., LeMar, H. J., WRIGHT, J. and THOMAS, J. (2001): Impairment in cognitive and exercise performance during prolonged Antarctic residence: Effect of thyroxine supplementation in the polar triiodothyronine syndrome. The Journal of Clinical Endocrinology and Metabolism, 86(1): 110-116.

Reed, H. L., Silverman, E. D., Shakir, K. M., Dons, R., Burman, K. D. and O'Brian, J. T. (1990): Changes in serum triiodothyronine (T3) kinetics after prolonged Antarctic residence: The polar T3 syndrome. The Journal of Clinical Endocrinology and Metabolism, 70(4): 965-974.

Russell, G., Lightman, S. (2019): The human stress response. Nature Reviews. Endocrinology, 15(9): 525-534.

Sandal, G. M., LeOn, G. R. and PalinKas, L. (2006): Human challenges in polar and space environments. Reviews in Environmental Science and Bio/Technology, 5: 281-296.

SCHEER, F. A., Buis, R. M. (1999): Light affects morning salivary cortisol in humans. The Journal of Clinical Endocrinology and Metabolism, 84(9): 3395-3398.

Schwabe, L., Haddad, L. and Schachinger, H. (2008): HPA axis activation by a socially evaluated cold-pressor test. Psychoneuroendocrinology, 33(6): 890-895.

SiLVA, J. E. (2001): The multiple contributions of thyroid hormone to heat production. The Journal of Clinical Investigation, 108(1): 35-37.

SiLVA, J. E. (1995): Thyroid hormone control of thermogenesis and energy balance. Thyroid: official journal of the American Thyroid Association, 5(6): 481-492.

Simmons, P. S., Miles, J. M., Gerich, J. E. and Haymond, M. W. (1984): Increased proteolysis. An effect of increases in plasma cortisol within the physiologic range. The Journal of Clinical Investigation, 73(2): 412-420.

Steinach, M., Kohlberg, E., Maggioni, M. A., Mendt, S., Opatz, O., Stahn, A. and Gunga, H. C. (2016): Sleep quality changes during overwintering at the german Antarctic stations Neumayer II and III: The Gender Factor. PloS One, 11(2): e0150099.

Strewe, C., Moser, D., Buchheim, J. I., Gunga, H. C., Stahn, A., Crucian, B. E., Fiedel, B., Bauer, H., Gössmann-Lang, P., Thieme, D., Kohlberg, E., Choukèr, A. and Feuerecker, M. (2019): Sex differences in stress and immune responses during confinement in Antarctica. Biology of Sex Differences, 10(1): 20. 
Y.A.T. MARTINS et al.

Sullivan, G. M., Feinn, R. (2012): Using effect size-or why the P value is not enough. Journal of Graduate Medical Education, 4(3): 279-282.

Terry, P. C., LANE, A. M. and Fogarty, G. J. (2003): Construct validity of the POMS-A for use with adults. Psychology of Sport and Exercise, 4: 125-139.

Terry, P. C., LANE, A. M., LANE, H. J. and KeOHANE, L. (1999): Development and validation of a mood measure for adolescents. Journal of Sports Sciences, 17(11): 861-872.

Tipton, M. (2012): A case for combined environmental stressor studies. Extreme Physiology \& Medicine, 1(1): 7.

Toyoda, N., Yasuzawa-Amano, S., Nomura, E., Yamauchi, A., Nishimura, K., Ukita, C., Morimoto, S., Kosaki, A., Iwasaka, T., Harney, J. W., Larsen, P. R. and Nishikawa, M. (2009): Thyroid hormone activation in vascular smooth muscle cells is negatively regulated by glucocorticoid. Thyroid official journal of the American Thyroid Association, 19(7): 755-763.

Tsibulnikov, S., Maslov, L., Voronkov, N. and Oeltgen, P. (2020): Thyroid hormones and the mechanisms of adaptation to cold. Hormones (Athens, Greece), 19(3): 329-339.

VAn Der Spoel, E., Roelfsema, F. and van Heemst, D. (2021): Within-Person variation in serum thyrotropin concentrations: Main sources, potential underlying biological mechanisms, and clinical implications. Frontiers in Endocrinology, 12: 619568.

Vingren, J. L., Kraemer, W. J., Ratamess, N. A., Anderson, J. M., Volek, J. S. and Maresh, C. M. (2010): Testosterone physiology in resistance exercise and training: The up-stream regulatory elements. Sports Medicine, 40(12): 1037-1053.

Vitale, J. A., Lombardi, G., Weydahl, A. and BAnfi, G. (2018): Biological rhythms, chronodisruption and chrono-enhancement: The role of physical activity as synchronizer in correcting steroids circadian rhythm in metabolic dysfunctions and cancer. Chronobiology International, 35(9): 1185-1197.

Wirth, M. M., Scherer, S. M., Hoks, R. M. and Abercrombie, H. C. (2011). The effect of cortisol on emotional responses depends on order of cortisol and placebo administration in a within-subject design. Psychoneuroendocrinology, 36(7): 945-954.

Woods, D. R., Delves, S. K., Britland, S. E., Shaw, A., Brown, P. E., Bentley, C., Hornby, S., Burnett, A., Lanham-New, S. A. and Fallowfield, J. L. (2015): Nutritional status and the gonadotrophic response to a polar expedition. Applied Physiology, Nutrition, and Metabolism, 40(3): 292-297.

Wright, K. P., Jr, Drake, A. L., Frey, D. J., Fleshner, M., Desouza, C. A., Gronfier, C. and CZEISLER, C. A. (2015): Influence of sleep deprivation and circadian misalignment on cortisol, inflammatory markers, and cytokine balance. Brain, Behavior, and Immunity, 47: 24-34.

Xu, C., Zhu, G., Xue, Q., Zhang, S., Du, G., XI, Y. and Palinkas, L. A. (2003): Effect of the Antarctic environment on hormone levels and mood of Chinese expeditioners. International Journal of Circumpolar Health, 62(3): 255-267.

Zimmer, M., Cabral, J. C. C. R., Borges, F. C., Côco, K. G. and Hameister, B. R. (2013): Psychological changes arising from an Antarctic stay: Systematic overview. Estudos de Psicologia (Campinas), 30(3): 415-423.

\section{Web sources / Other sources}

[1] Zone-related website Time and Date. (2017) Livingston Island, Antarctica Sunrise, Sunset, and Daylength, January 2017 [Online]. https://www.timeanddate.com/sun/@6620723?month=1\&year=2017 (Accessed: 10 October 2020).

[2] B032-312 AutoDELFIA Neonatal hTSH 2016. Instructions for use. PerkinElmer: 2016, Wallac Oy, Turku, Finland.

[3] B065-112 AutoDELFIA Neonatal Thyroxine (T4) 2016. Instructions for use. PerkinElmer: 2016, Wallac Oy, Turku, Finland. 


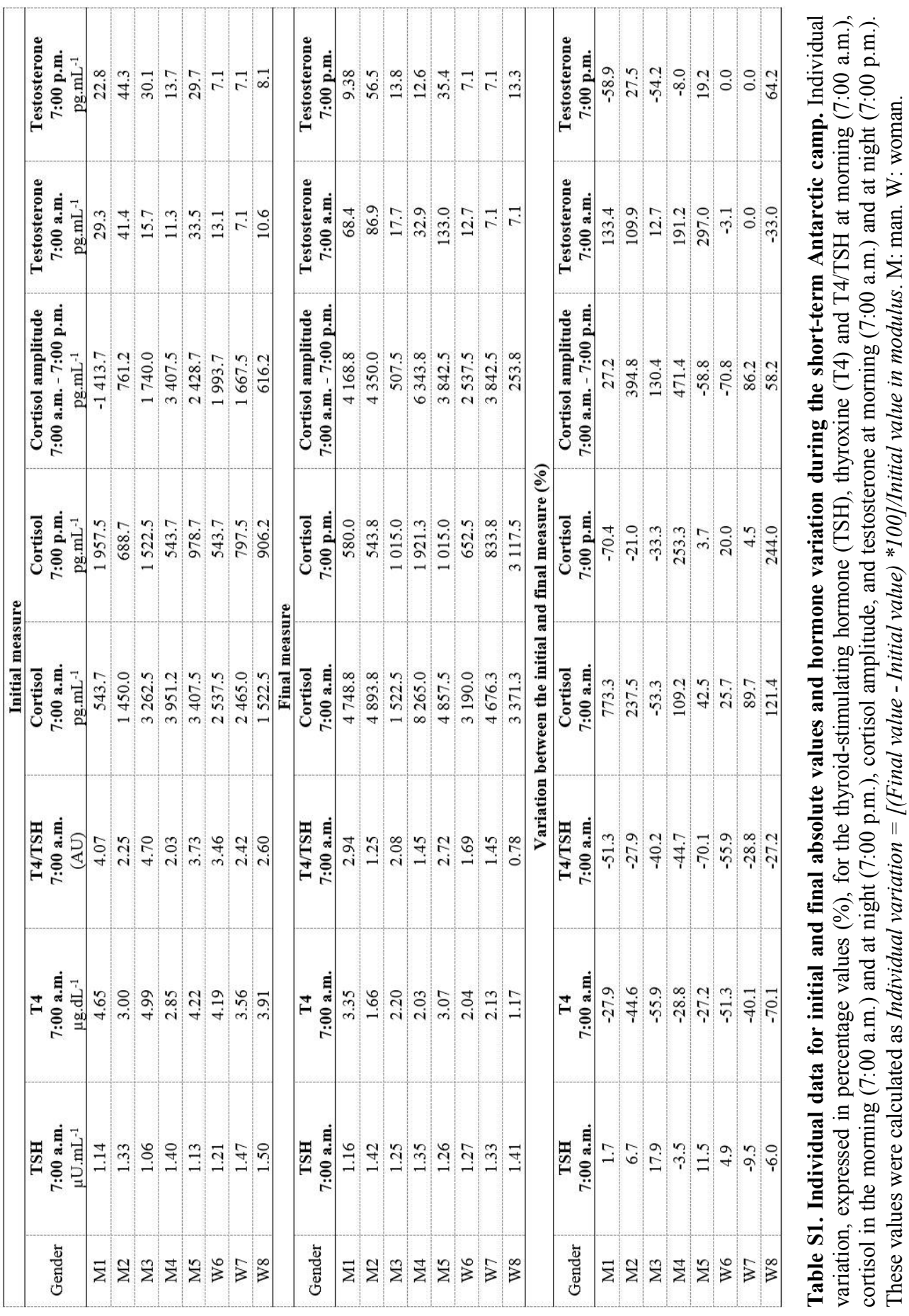


Skin temperatures and perceptual responses measured in six volunteers in a sheltered environment (heated tent) and outdoors during a typical day in the Antarctic camp

This is supplemental material for the article: An exploratory study of short-term camping in Antarctica: Hormonal and mood states changes authored by Martins, Y. A. T., Moraes, M. M., Mendes, T. T., Maluf, C. B., Ladeira, R. V. P., Wanner, S. P., Soares, D. D., Arantes, R. M. E

\begin{tabular}{|c|c|c|c|c|c|c|c|c|}
\hline & \multicolumn{4}{|c|}{ Sheltered environment } & \multicolumn{4}{|c|}{ Outdoors } \\
\hline & $\begin{array}{c}\text { Initial } \\
\text { measure } \\
3^{\text {rd }} \text { to } 5^{\text {th }} \\
\text { day }\end{array}$ & $\begin{array}{c}\text { Final } \\
\text { measure } \\
10^{\text {th }} \text { to } 12^{\text {th }} \\
\text { day }\end{array}$ & $\begin{array}{c}P- \\
\text { value }\end{array}$ & $E S$ & $\begin{array}{c}\text { Initial } \\
\text { measure } \\
3^{\text {rd }} \text { to } 5^{\text {th }} \\
\text { day }\end{array}$ & $\begin{array}{c}\text { Final } \\
\text { measure } \\
10^{\text {th }} \text { to } 12^{\text {th }} \\
\text { day }\end{array}$ & $\begin{array}{c}P- \\
\text { value }\end{array}$ & $E S$ \\
\hline \multicolumn{9}{|c|}{ Skin temperatures $\left({ }^{\circ} \mathrm{C}\right)$} \\
\hline Cheek & $26.7 \pm 2.0$ & $26.8 \pm 1.7$ & 0.99 & 0.01 & $16.6 \pm 3.7$ & $22.2 \pm 4.3$ & 0.08 & $1.39^{\mathrm{VL}}$ \\
\hline Chin & $27.7 \pm 3.5$ & $27.5 \pm 3.8$ & 0.87 & 0.06 & $17.1 \pm 7.7$ & $23.3 \pm 3.6^{*}$ & 0.03 & $1.03^{\mathrm{L}}$ \\
\hline Ear canal & $35.2 \pm 0.3$ & $35.6 \pm 0.2$ & 0.26 & $1.34^{\mathrm{VL}}$ & $35.2 \pm 0.2$ & $35.1 \pm 0.3$ & 0.89 & 0.06 \\
\hline Forehead & $30.8 \pm 2.0$ & $30.4 \pm 1.9$ & 0.55 & 0.23 & $19.8 \pm 4.3$ & $25.4 \pm 4.7^{*}$ & 0.04 & $1.25^{\mathrm{L}}$ \\
\hline Hand & $24.3 \pm 3.0$ & $24.3 \pm 4.5$ & 0.99 & $<0.01$ & $18.4 \pm 2.5$ & $20.0 \pm 4.7$ & 0.28 & 0.42 \\
\hline Nose & $23.3 \pm 5.7$ & $21.7 \pm 2.8$ & 0.46 & 0.34 & $15.5 \pm 4.5$ & $16.7 \pm 4.3$ & 0.52 & 0.28 \\
\hline \multicolumn{9}{|c|}{ Perceptual responses } \\
\hline Thermal comfort & $-0.7 \pm 3.9$ & $-0.1 \pm 3.8$ & 0.83 & 0.14 & $-5.9 \pm 1.5$ & $-6.2 \pm 2.6$ & 0.81 & 0.13 \\
\hline $\begin{array}{l}\text { Thermal } \\
\text { sensation }\end{array}$ & $-0.1 \pm 3.7$ & $-1.8 \pm 2.7$ & 0.18 & $0.53^{\mathrm{M}}$ & $-6.3 \pm 1.1$ & $-6.7 \pm 2.1$ & 0.69 & 0.23 \\
\hline
\end{tabular}

Table S2. Facial temperatures and perceptual variables measured in the beginning (initial measure) and at the end (final measure) of the short-term Antarctic camp.

The facial and hand temperatures and perceptual responses were measured in six volunteers in the morning, between 7:00 a.m. and 8:00 a.m., at two conditions: the "sheltered environment" in a heated tent (ambient temperature days 3-5: $27.1 \pm 1.1^{\circ} \mathrm{C}$ vs. days 10-12: $\left.26.7 \pm 1.6^{\circ} \mathrm{C} ; P=0.45 ; E S=0.1\right)$, and outdoors, outside the tent (ambient temperature days 3-5: $2.2 \pm 0.2^{\circ} \mathrm{C} v s$. days $10-12: 2.6 \pm 0.8^{\circ} \mathrm{C} ; P=0.17$; $E S=0.5$ ). Considering the oscillations of the external environment, the weather forecast was followed to plan data collections in typical days of the Antarctic summer and ensure the closest climatic conditions between the different experimental days for the same individual. The volunteers spent 20 minutes sitting in the "sheltered environment" and then 20 minutes sitting outdoors. In both conditions, the following measurements were made every five minutes: skin temperature - forehead, cheek, chin, nose, and hand (performed with an infrared sensor Fluke 568 (C) 1995-2010 Fluke Corporation, OH, USA), ear canal temperature (G-TECH, model IR1DB1, Accumed, RJ, BR), thermal comfort, and thermal sensation [1].

Statistical analysis: Paired Student's t-tests. Data are expressed as means $\pm \mathrm{SD}$. Temperature of the ear canal, $\mathrm{n}=4$. Cohen's $d$ effect sizes $(E S)$ were calculated to assess the magnitude of the difference between experimental time points. ${ }^{\mathrm{M}}$ Moderate effect size; ${ }^{\mathrm{L}}$ Large effect size; ${ }^{\mathrm{VL}}$ Very large effect size.

[1] Nakamura, M., Yoda, T., Crawshaw, L. I., Kasuga, M., Uchida, Y., Tokizawa, K., NAGASHIMA, K., KANOSUE, K. (2013): Relative importance of different surface regions for thermal comfort in humans. European Journal of Applied Physiology, 113(1): 63-76. 